\title{
Histopathological Analysis of False-positive Lesions in mpMRI/TRUS Fusion Prostate Biopsy
}

\author{
RYOKEN YAMANAKA ${ }^{1}$, YOHEI SEKINO ${ }^{1}$, TAKASHI BABASAKI ${ }^{1}$, KOHEI KOBATAKE $^{1}$, \\ HIROYUKI KITANO ${ }^{1}$, KENICHIRO IKEDA ${ }^{1}$, KEISUKE GOTO ${ }^{1}$, TETSUTARO HAYASHI $^{1}$, JUN TEISHIMA ${ }^{1}$, \\ YUKIO TAKESHIMA ${ }^{2}$, YUKIKO HONDA ${ }^{3}$, KAZUO AWAI ${ }^{3}$ and NOBUYUKI HINATA ${ }^{1}$ \\ ${ }^{1}$ Department of Urology, Graduate School of Biomedical and Health Sciences, \\ Hiroshima University, Hiroshima, Japan; \\ ${ }^{2}$ Department of Pathology, Graduate School of Biomedical and Health Sciences, \\ Hiroshima University, Hiroshima, Japan; \\ ${ }^{3}$ Department of Diagnostic Radiology, Graduate School of Biomedical \\ and Health Sciences, Hiroshima University, Hiroshima, Japan
}

\begin{abstract}
Background/Aim: Multi-parametric magnetic resonance imaging $(m p M R I) /$ ultrasonography fusion prostate biopsy $(F B)$ is a more accurate method of diagnosis than conventional prostate biopsy, but false-positive lesions still exist. Limited studies have examined the cause of false-positive lesions by histological analysis. Patients and Methods: We examined 322 patients who underwent mpMRI/transrectal ultrasonography (TRUS) FB. We classified prostate imaging-recording and data system (PI-RADS) 3 and PI-RADS 4-5 as low PI-RADS lesions and high PI-RADS lesions, respectively. In total, 105 lesions were identified as false-positive lesions. We performed histological analysis of atrophy, hyperplasia, and lymphocyte infiltration in these lesions, comparing low PI-RADS lesions and high PI-RADS lesions. Results: The frequencies of prostate hyperplasia and lymphocyte infiltration were higher in high PI$R A D S$ lesions than in low PI-RADS lesions ( $p=0.028$ and 0.024 , respectively). There was no significant difference regarding atrophy ( $p=0.295)$. Conclusion: Histopathological change may be one of the reasons for false-positive lesions.
\end{abstract}

The standard method of diagnosing prostate cancer (PCa) is transrectal ultrasonography (TRUS)-guided prostate biopsy (PB). However, TRUS-guided PB often fails to detect PCa

This article is freely accessible online.

Correspondence to: Yohei Sekino, MD, Ph.D., Department of Urology, Graduate School of Biomedical and Health Sciences, Hiroshima University, 1-2-3 Kasumi, Minami-ku, Hiroshima 7348551, Japan. Tel: +81 822575146, Fax: +81 822575149, e-mail: akikosekino@gmail.com

Key Words: Prostate cancer, fusion biopsy, PI-RADS, false positive. because of insufficient ability to distinguish malignant tissues from benign prostatic tissues (1). Furthermore, PB is a stressful and painful examination. To improve the accuracy of $\mathrm{PCa}$ detection and reduce unnecessary biopsies, multiparametric magnetic resonance imaging (mpMRI) has been used in the past decade (2). Further, for the standardised reporting of mpMRI, the Prostate Imaging-Recording and Data System (PIRADS), was introduced in 2012 (3). Several recent clinical studies have shown that fusion-guided prostate biopsy (FB), which combines mpMRI with TRUS-guided PB, is a superior method compared to the conventional TRUS-guided PB $(4,5)$. Indeed, we previously reported that FB improved the accuracy of the detection of clinically significant PCa (6).

Although the accuracy of PB has improved, false-positive lesions exist that are suspicious for PCa on mpMRI but not diagnosed as $\mathrm{PCa}$ by $\mathrm{PB}$. A recent study reviewed the technical reasons for false-positive lesions (7). Meanwhile, several studies reported the impact of histological alterations on the PI-RADS score. Recent studies showed that $18 \%$ of PI-RADS 5 lesions (18/98) were identified as non-cancerous lesions, and inflammatory changes were observed in $28 \%$ (5/18) of the falsepositive lesions (8). One study reported that chronic inflammation and basal cell hyperplasia are associated with lesions falsely suspicious for PCa by comparing target biopsy tissues with standard biopsy tissues (9). Another recent study showed that histological changes such as stromal, glandular, vascular, and inflammatory alterations were observed in false-positive lesions by comparing target biopsy tissues with standard biopsy tissues (7). These findings indicate that histological alterations may influence the PI-RADS score. However, there are few reports on the histopathological analysis of false-positive lesions. Therefore, we focused on the histopathological changes in false-positive lesions comparing low PI-RADS lesions with high PI-RADS lesions. The pathological findings of atrophy, hyperplasia, and 

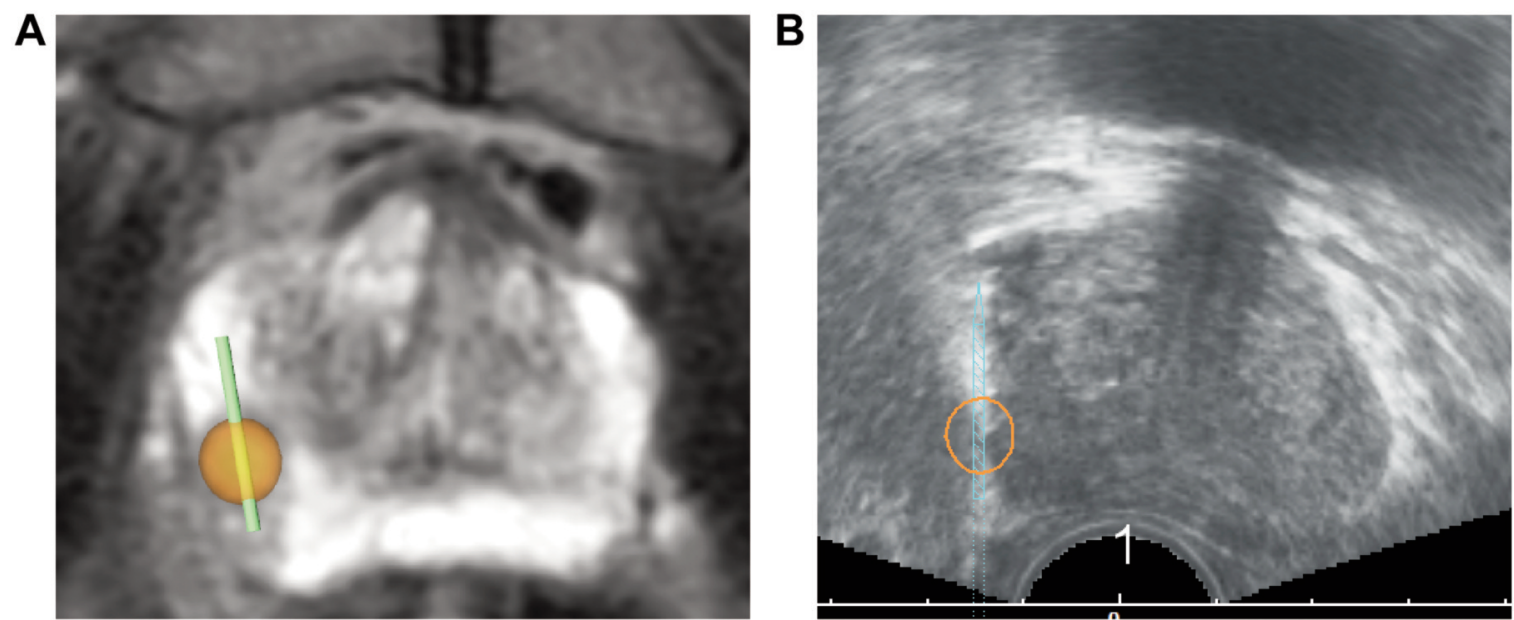

Figure 1. Representative images of multiparametric MRI/ultrasonography fusion biopsy. Image of multiparametric MRI. Circle: region of interest. Line: biopsy line. (B) Image of transrectal ultrasonography. Circle: region of interest. Line: biopsy line.

lymphocyte infiltration are often observed in tissues from PB. Therefore, in this study, we performed histopathological analysis of the false-positive lesions to clarify the mechanism of the different findings between mpMRI and PB.

\section{Patients and Methods}

Patient characteristics. The patients with elevated prostate-specific antigen (PSA) levels were found to have lesions suspicious of $\mathrm{PCa}$ on mpMRI and subsequently received mpMRI/ultrasonography FB (Figure 1) together with additional 10-core systematic biopsies. Between February 2015 and January 2019, we performed mpMRI/ultrasonography FB in 322 patients at Hiroshima University Hospital. Two radiologists reassessed all MRI scans according to PIRADS version 2.1 (10). We identified 322 PI-RADS scores in 322 patients. When multiple PI-RADS scores were found by mpMRI, we considered the highest PI-RADS score as the representative PI-RADS score in each patient. Seven urologists performed FB with the help of the Trinity ${ }^{\circledR}$ Image-Fusion system (Koelis, Grenoble, France). FB was performed with the patient in the lithotomy position by the transrectal approach under local anaesthesia. We punctured 2-4 cores per each representative PI-RADS 1-5 lesion. A single urologist (author) compared all specimens histopathologically, stained them with hematoxylin and eosin, and scored them in terms of atrophy, hyperplasia, and lymphocyte infiltration. They were rated using a three-grade scale: high, middle, and low.

Statistical analysis. All statistical analyses were performed using JMP Pro version 13 (SAS institute Inc, Cary, NC, USA). Comparisons between patient groups were assessed using the Chisquare test. $p$-Values $<0.05$ were considered significant.

\section{Results}

Among the 322 patients, 46 were excluded because they showed PI-RADS 1-2. Seventy-nine showed low PI-RADS lesions, and $26.6 \%$ of them (21/79) were diagnosed as PCa. The other $73.4 \%(58 / 79)$ of the lesions were false-positive lesions. In contrast, 197 patients showed high PI-RADS lesions, and $76.1 \%$ of them (150/197) were pathologically diagnosed as PCa. The other 23.1\% (47/197) of the lesions were false-positive lesions. In total, 105 lesions were identified as false-positive lesions (Figure 2). Table I shows the clinical features of the 105 false-positive lesions. The 47 high PI-RADS lesions included 37 PI-RADS 4 lesions and 10 PI-RADS 5 lesions. A comparison of the characteristics of the patients with high PI-RADS and low PI-RADS lesions showed median patient ages of 69 (range=37-86 years) and 69 (range $=53-81$ years), median patient PSA values of 7.9 $\mathrm{ng} / \mathrm{ml}$ (range=0.6-31.4 ng/ml) and 6.1 (range=1.6-22.9 $\mathrm{ng} / \mathrm{ml})$, and median prostate volumes of $53.0 \mathrm{ml}$ (range=25.3-128.2 $\mathrm{ml}$ ) and 52.2 (range=24.4-138.5 ml), respectively. There were no significant differences in the values of age, PSA, and prostate volume between the patients with low PI-RADS lesions versus those with high PI-RADS lesions ( $p=0.512,0.076$, and 0.336 , respectively).

We performed histopathological analysis of the falsepositive lesions mainly focusing on atrophy, hyperplasia, and lymphocyte infiltration. Representative images of atrophy, hyperplasia, and lymphocyte infiltration are shown in Figure 3. We rated each lesion on a three-grade scale as high: 3 points, middle: 2 points, and low: 1 point. The results of the histopathological differences between the low PI-RADS lesions and high PI-RADS lesions are shown in Table II. The values for hyperplasia and lymphocyte infiltration were higher in the high PI-RADS lesions than those in the low PIRADS lesions ( $p=0.028$ and 0.024 , respectively). There was no significant difference for atrophy $(p=0.295)$ between the two lesion types. 


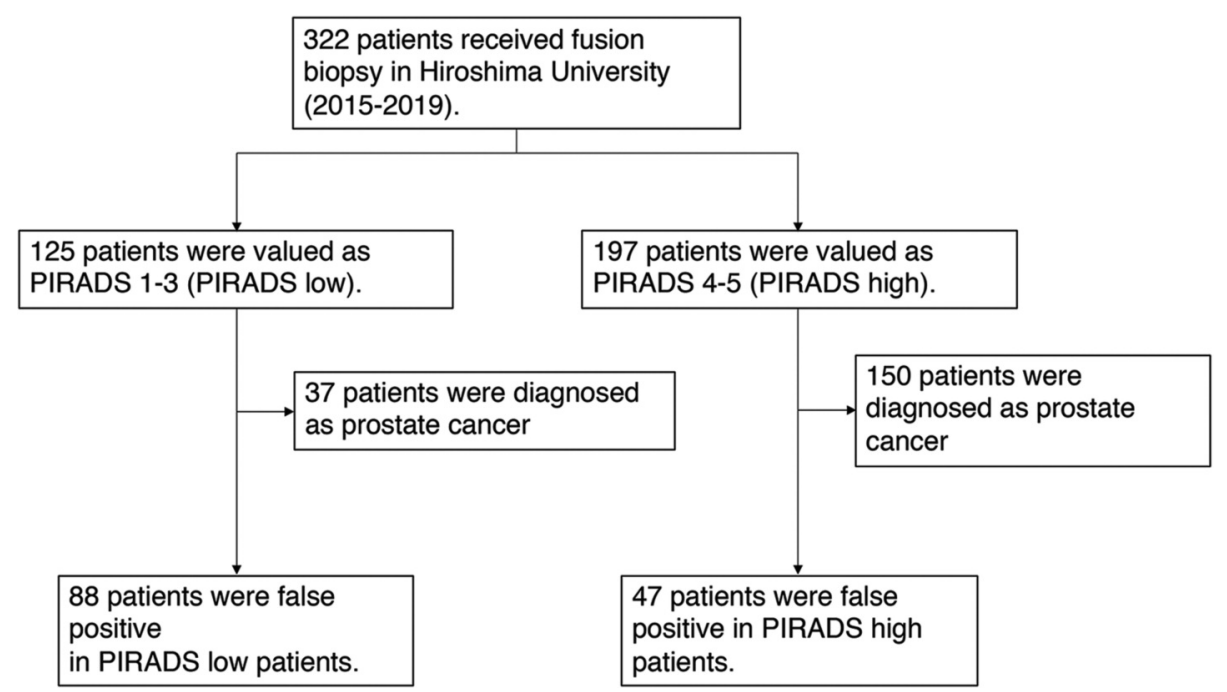

Figure 2. Flow chart of patient selection.

Table I. Clinical features of false positive lesions.

\begin{tabular}{lccc}
\hline & $\begin{array}{c}\text { PI-RADS } \\
\text { low lesions }\end{array}$ & $\begin{array}{c}\text { PI-RADS } \\
\text { high lesions }\end{array}$ & $p$-Value \\
\hline $\begin{array}{l}\text { The number } \\
\text { of patients }\end{array}$ & 58 & 47 & \\
$\begin{array}{l}\text { PI-RADS 3 } \\
\text { PI-RADS 4 }\end{array}$ & 58 & & \\
$\begin{array}{l}\text { PI-RADS 5 } \\
\begin{array}{l}\text { Median age } \\
\text { (range) }\end{array}\end{array}$ & $69(53-81)$ & $69(37-86)$ & 0.512 \\
$\begin{array}{l}\text { Median PSA value } \\
\text { [ng/ml] (range) }\end{array}$ & $6.1(1.6-22.9)$ & $7.9(0.6-31.4)$ & 0.076 \\
$\begin{array}{l}\text { Median prostate } \\
\text { volume [ml] (range) }\end{array}$ & $52.2(24.4-138.5)$ & $53.0(25.3-128.2)$ & 0.336 \\
\hline
\end{tabular}

PI-RADS: Prostate Imaging-Recording and Data System.

\section{Discussion}

Although the PROMIS study, one of the key clinical trials, has shown that FB is more sensitive for the diagnosis of clinically significant cancer $(93 \%)$ than conventional PB (41\%) (4), false-positive lesions exist. Our report showed that the values for hyperplasia and lymphocyte infiltration were higher in high PI-RADS lesions than in low PI-RADS lesions. To the best of our knowledge, this study is the first to histopathologically analyse low PI-RADS lesions in comparison with high PI-RADS lesions in FB.

Prostatic intra-epithelial neoplasia (PIN) and proliferative inflammatory atrophy (PIA) are widely known to be precursors of PCa (11). Several studies have shown that disruption of the basal cell layer is indicated as a cause of
Table II. Average value of histopathological parameters in prostate with false-positive patients from $\mathrm{FB}$.

\begin{tabular}{lccc}
\hline & $\begin{array}{c}\text { PI-RADS } \\
\text { low lesions } \\
\mathrm{n}=58\end{array}$ & $\begin{array}{c}\text { PI-RADS } \\
\text { high lesions } \\
\mathrm{n}=47\end{array}$ & $p$-Value \\
\hline Atrophy & & & \\
Low (1 points) & 5 & 6 & \\
Middle (2 points) & 22 & 23 & \\
High (3 point) & 31 & 18 & 0.295 \\
Average value & 2.448 & 2.255 & \\
Hyperplasia & & & \\
Low (1 points) & 18 & 5 & 0.028 \\
Middle (2 points) & 24 & 21 & \\
High (3 point) & 16 & 21 & \\
Average value & 1.966 & & \\
Lymphocyte infiltration & & 8 & \\
Low (1 points) & 12 & 21 & \\
Middle (2 points) & 23 & 18 & \\
High (3 point) & 23 & 2.213 & 0.024 \\
Average value & 1.810 & & \\
\hline
\end{tabular}

PI-RADS: Prostate Imaging-Recording and Data System; FB: prostate biopsy.

cancer, inflammation, and high-grade PIN $(12,13)$. It has been shown that atrophy and inflammation can be the precursors of high-grade PIN and PCa (11). Hyperplasia and lymphocyte infiltration that is caused by chronic inflammation might also influence prostate carcinogenesis (11). These findings indicated that hyperplasia and lymphocyte infiltration may be possible precursors of $\mathrm{PCa}$. In our study, the values of hyperplasia and lymphocyte infiltration were higher in the high PI-RADS lesions than in the low PI-RADS lesions, 

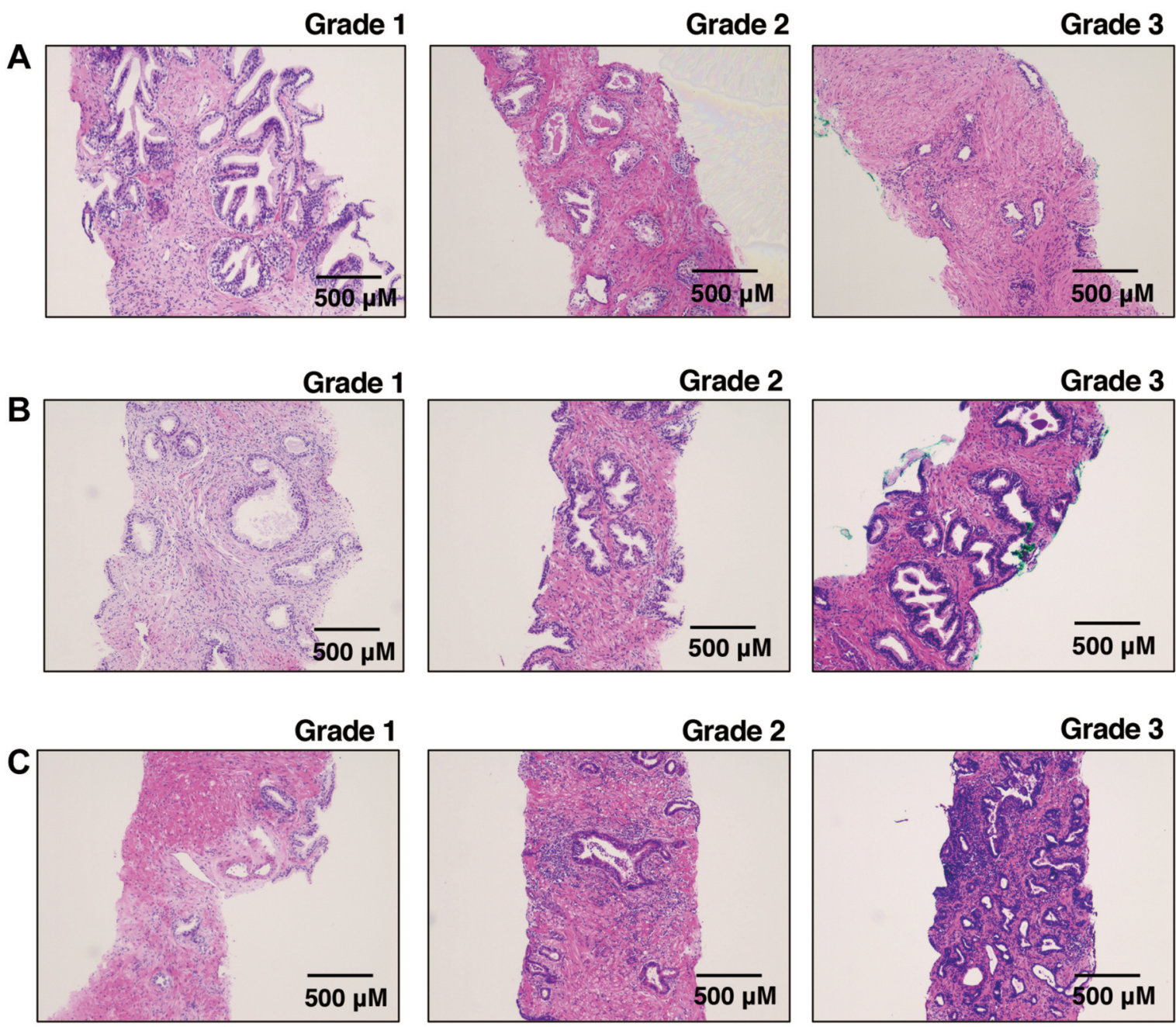

Figure 3. Representative images of hematoxylin and eosin staining of atrophy, hyperplasia, and lymphocyte infiltration. (A) Atrophy. Grade 1: glands showing a lobular pattern. Grade 2: glands with partial atrophy. Grade 3: glands with atrophy. Magnification 40x. (B) Hyperplasia. Grade 1: uniform and less basophilic-appearing basal cells. Grade 2: variably sized basophilic glands. Grade 3: glands showing emphasised and darken basophilic basal cells. Magnification 40x. (C) Lymphocyte infiltration. Grade 1: low infiltration of inflammatory cells. Grade 2: inflammatory cells in the stroma. Grade 3: greater presence of inflammatory cells in stroma that are darker. Magnification 40x.

suggesting that hyperplasia and lymphocyte infiltration as precursors of PCa may affect the PI-RADS score.

PI-RADS includes scores of mpMRI of three images, T2weighted imaging, diffusion-weighted imaging (DWI), and dynamic contrast-enhanced imaging (3). Considering the mechanism of MRI, the density of water molecules affects the score of DWI. Tissues with high water content cause an increased signal on T2 weighted imaging (14). One report showed that an open cellular architecture such as that in cribriform tumours could allow water molecules to move more easily (15). The status of a dense cellular pattern in hyperplasia and lymphocyte infiltration can also influence the score of DWI. These findings may help to explain the reason why the values of hyperplasia and lymphocyte infiltration were higher in high PI-RADS versus low PIRADS lesions.

This study has some limitations. First, this study is retrospective, and the number of specimens is limited. Second, multiple surgeons (seven urologists) performed FB. As mentioned in the introduction, technical errors influence the ratio of false-positive lesions. Lesions detected on mpMRI may not be perfectly comparable with those detected with FB.

\section{Conclusion}

Prostate hyperplasia and lymphocyte infiltration were more frequently observed in high PI-RADS lesions than in low PIRADS lesions. Histopathological change might be one of the 
reasons for false-positive lesions along with surgical proficiency, the context of the target biopsy of mpMRI, and other background factors.

\section{Conflicts of Interest}

The Authors declare no conflicts of interest in relation to this study.

\section{Authors' Contributions}

YS, and NH designed the study. TB, KK, HK, KI, KG, and TH provided patients' clinical information. RY, JT, YT, YH, and KA performed experiments and acquired data. YH and YT interpreted the results. RY drafted the manuscript. YS edited the article. All Authors approved the final content for journal submission and publication.

\section{Acknowledgements}

The Authors thank Mr. Shinichi Norimura for his excellent technical assistance. This work was carried out with the kind cooperation of the Research Center for Molecular Medicine of the Faculty of Medicine of Hiroshima University. The Authors would like to thank the Analysis Center of Life Science of Hiroshima University for the use of their facilities. This work was supported by the Japan Society for the Promotion of Science [19K18586].

\section{References}

1 Lomas DJ and Ahmed HU: All change in the prostate cancer diagnostic pathway. Nat Rev Clin Oncol 17(6): 372-381, 2020. PMID: 32112055. DOI: 10.1038/s41571-020-0332-z

2 Stabile A, Giganti F, Rosenkrantz AB, Taneja SS, Villeirs G, Gill IS, Allen C, Emberton M, Moore CM and Kasivisvanathan V: Multiparametric MRI for prostate cancer diagnosis: current status and future directions. Nat Rev Urol 17(1): 41-61, 2020. PMID: 31316185. DOI: 10.1038/s41585-019-0212-4

3 Weinreb JC, Barentsz JO, Choyke PL, Cornud F, Haider MA, Macura KJ, Margolis D, Schnall MD, Shtern F, Tempany CM, Thoeny HC and Verma S: PI-RADS prostate imaging - reporting and data system: 2015, version 2. Eur Urol 69(1): 16-40, 2016. PMID: 26427566. DOI: 10.1016/j.eururo.2015.08.052

4 Ahmed HU, El-Shater Bosaily A, Brown LC, Gabe R, Kaplan R, Parmar MK, Collaco-Moraes Y, Ward K, Hindley RG, Freeman A, Kirkham AP, Oldroyd R, Parker C, Emberton M and PROMIS study group: Diagnostic accuracy of multiparametric MRI and TRUS biopsy in prostate cancer (PROMIS): a paired validating confirmatory study. Lancet 389(10071): 815-822, 2017. PMID: 28110982. DOI: 10.1016/ S0140-6736(16)32401-1

5 Kasivisvanathan V, Rannikko AS, Borghi M, Panebianco V, Mynderse LA, Vaarala MH, Briganti A, Budäus L, Hellawell G, Hindley RG, Roobol MJ, Eggener S, Ghei M, Villers A, Bladou F, Villeirs GM, Virdi J, Boxler S, Robert G, Singh PB, Venderink W, Hadaschik BA, Ruffion A, Hu JC, Margolis D, Crouzet S, Klotz L, Taneja SS, Pinto P, Gill I, Allen C, Giganti F, Freeman A, Morris S, Punwani S, Williams NR, Brew-Graves C, Deeks J, Takwoingi Y, Emberton M, Moore CM and PRECISION Study Group Collaborators: MRI-targeted or standard biopsy for prostate-cancer diagnosis. N Engl J Med 378(19): 1767-1777, 2018. PMID: 29552975. DOI: 10.1056/ NEJMoa1801993

6 Fujii S, Hayashi T, Honda Y, Terada H, Akita R, Kitamura N, Ueda E, Han X, Ueno T, Miyamoto S, Kitano H, Inoue S, Teishima J, Abdi H, Awai K, Takeshima Y, Sentani K, Yasui W and Matsubara A: Magnetic resonance imaging/transrectal ultrasonography fusion targeted prostate biopsy finds more significant prostate cancer in biopsy-naïve Japanese men compared with the standard biopsy. Int J Urol 27(2): 140-146, 2020. PMID: 31733635. DOI: 10.1111/iju.14149

7 Hupe MC, Offermann A, Tharun L, Fürschke A, Frydrychowicz A, Garstka N, Shariat SF, Barkhausen J, Merseburger AS, Kramer MW and Perner S: Histomorphological analysis of false positive PIRADS 4 and 5 lesions. Urol Oncol 38(7): 636.e7-636.e12, 2020. PMID: 32113858. DOI: 10.1016/j.urolonc.2020.01.017

8 Sheridan AD, Nath SK, Aneja S, Syed JS, Pahade J, Mathur M, Sprenkle P, Weinreb JC and Spektor M: MRI-ultrasound fusion targeted biopsy of prostate imaging reporting and data system version 2 category 5 lesions found false-positive at multiparametric prostate MRI. AJR Am J Roentgenol 210(5): W218-W225, 2018. PMID: 29489409. DOI: 10.2214/AJR.17.18680

9 Gordetsky JB, Ullman D, Schultz L, Porter KK, Del Carmen Rodriguez Pena M, Calderone CE, Nix JW, Ullman M, Bae S and Rais-Bahrami S: Histologic findings associated with falsepositive multiparametric magnetic resonance imaging performed for prostate cancer detection. Hum Pathol 83: 159-165, 2019. PMID: 30179687. DOI: 10.1016/j.humpath.2018.08.021

10 Turkbey B, Rosenkrantz AB, Haider MA, Padhani AR, Villeirs G, Macura KJ, Tempany CM, Choyke PL, Cornud F, Margolis DJ, Thoeny HC, Verma S, Barentsz J and Weinreb JC: Prostate imaging reporting and data system version 2.1: 2019 update of prostate imaging reporting and data system version 2. Eur Urol 76(3): 340-351, 2019. PMID: 30898406. DOI: 10.1016/j.eururo. 2019.02.033

11 Palapattu GS, Sutcliffe S, Bastian PJ, Platz EA, De Marzo AM, Isaacs WB and Nelson WG: Prostate carcinogenesis and inflammation: emerging insights. Carcinogenesis 26(7): 11701181, 2005. PMID: 15498784. DOI: 10.1093/carcin/bgh317

12 Cheng L, Shan A, Cheville JC, Qian J and Bostwick DG: Atypical adenomatous hyperplasia of the prostate: a premalignant lesion? Cancer Res 58(3): 389-391, 1998. PMID: 9458077.

13 Epstein JI: Precursor lesions to prostatic adenocarcinoma. Virchows Arch 454(1): 1-16, 2009. PMID: 19048290. DOI: 10.1007/s00428-008-0707-5

14 Chatterjee A, Harmath $\mathrm{C}$ and Oto A: New prostate MRI techniques and sequences. Abdom Radiol (NY) 45(12): 40524062, 2020. PMID: 32248259. DOI: 10.1007/s00261-02002504-8

15 Truong M, Hollenberg G, Weinberg E, Messing EM, Miyamoto $\mathrm{H}$ and Frye TP: Impact of Gleason subtype on prostate cancer detection using multiparametric magnetic resonance imaging: Correlation with final histopathology. J Urol 198(2): 316-321, 2017. PMID: 28163032. DOI: 10.1016/j.juro.2017.01.077

Received October 23, 2021

Revised November 18, 2021 Accepted November 19, 2021 